\title{
Antroposeenin ruokaympyrä ja kriittinen monilajinen kasvatustiede
}

\author{
$y$ \\ "Liha- vai kasvisruoka" on kysymys, josta on hyvä lähteä \\ liikkeelle. Mutta kriittisen monilajisen kasvatustieteen \\ ja pedagogiikan tulokulmasta pitäisi lisäksi kysyä: \\ mikä liha, mikä kasvis, keiden kustannuksella, keiden \\ hyödyksi, millaisia historioita vaalien?
}

FILOSOFI ANNEMARIE MOL (2008) muisteli tarinaa lapsuudestaan, joka meni näin. Ulkoavaruuden olio raportoi vierailustaan maassa: "Kiinnostava planeetta. Sitä asuttavat erikokoiset ja erilaisissa ympäristöissä elävät ruohot, joille kaksijalkaiset otukset tekevät töitä. Kaksijalkaiset oliot ovat levittäneet nämä ruohot pallon joka kolkkaan ja tuhonneet muut kasvit, jotta ne eivät häiritse ruohojen kasvua liiaksi. Kauden tullessa päätökseen kaksijalkaiset keräävät ruohot ja erottelevat jyvät, jotta voivat taas tilaisuuden tullen kylvää ne. Osan jyvistä nämä oliot syövät, mutta vuosi vuodelta ruohojen elinalue laajenee. Se on todella vakuuttavaa."

Tarina säröttää tarinoita ihmisestä, joka käyttää luonnonvaroja omien päämääriensä toteuttami- seen ja katsoo toimintansa seuraukset niin hyvässä kuin pahassa omaksi ansiokseen ja ympäristönsä pelkäksi mykäksi taustaksi. Puhutaan aikakaudesta, jonka aikana ihmisen toiminta on alkanut muuttaa maapallojärjestelmiä. Puhutaan ihmisen ajasta, antroposeenista. Voihan olla niin, että vaikkapa monet nykyisistä haitallisiksi määritellyistä vieraslajeista ovat onnistuneet alun perin houkuttamaan matkustamaan etuoikeutettuja eurooppalaisia viehättävyydellään luokseen, saaneet nämä ihmiset keräämään niitä, kuljettamaan uusiin elinympäristöihin ja hoitamaan niitä. Joillekin vieraslajeille on varta vasten raivattu yksilajisia alueita, sillä on huomattu niiden soveltuvan ihmisten ravinnoksi ja rehuksi, 


\section{PANDEMIA ON PAKOTTANUT}

TARKASTELEMAAN IHMISTEN

JA MUIDEN EL ̈̈INTEN

SUHTEITA JA NIISS $\ddot{A}$

MATERIALISOITUVIEN

EPÄOIKEUDENMUKAISUUKSIEN

SEURAUKSIA.

kykenevän kasvamaan monenlaisissa ympäristöissä ja mahdollisesti kohtuullisen vähäisellä vaivalla. Materiaa on arvotettu - mikä esimerkiksi on ruuaksi tai vaatteeksi paremmin ja huonommin kelpaavaa. Materialle on myös annettu rahallinen arvo, ja maan ja sen olentojen muokkauksen tärkeäksi pyrkimykseksi on muodostunut lisäarvon tuottaminen, ei esimerkiksi monilajisuuden vaaliminen.

On muutakin. Viljellyistä ruohoista suuri osa ei suinkaan päädy ihmisten vaan siivekkäiden ja nelijalkaisten ruuaksi, joita ihmiset ovat enenevässä määrin alkaneet pitää piilossa rakennelmissaan. Ehkäpä ulkoavaruuden olion vierailu tapahtui ennen 1950-luvun "suurta kiihdytystä" ja siihen kuulunutta eläinten tehotuotannon räjähdysmäistä kasvua osana laajempaa luonnonvarojen törsäystä.

Tai ehkä kyseessä oli 1600-luvun Amerikka. Suinkaan kaikki kaksijalkaisista eivät puurra plantaaseilla: ainoastaan ne, joita oikeutettuina itseään pitävät kohtelevat kuin mitä tahansa muutakin tavaraa. Olio huomaa, mutta jättää raportoimatta, että tällainen epäoikeudenmukaisuuden rakenne alkaa toistua vuosisadasta toiseen ja siitä hyötyvät koettavat piilottaa sen milloin minkäkin oikeutuksen ja teorian taakse.

Myös kamppailuja käydään ja toimenpiteitä toteutetaan orjuuden ja orjuuttamisen eri muotojen kitkemiseksi ja liberaalin subjektin kategorian laajentamiseksi. Orjuuden kieltäminen lailla, lapsityövoiman kriminalisointi, liberaalin demokratian laajeneminen innostavat tarinamme oliota. Ne myös vaivaannuttavat: miksi näiden uudistusten pohjavire on ollut sisällyttäminen dominoivaan järjestelmään perustavanlaatuisen uudelleenorganisoinnin sijaan?

\section{IHMISEN AIKA}

Ihmismaantieteilijä Kathryn Yusoff (2018) vetää meidät takaisin multaan ja vaatii vastaamaan, minkä tähden nyt kelpaa puhua antroposeenin universaalista ihmisestä ikään kuin kaikki olisivat samalla tavoin syypäitä maapallojärjestelmien muutoksiin ja ikään kuin nämä muutokset vaikuttaisivat jokaiseen samalla tavoin ja samalla hetkellä! On kait jokseenkin eri asia elää nykylapsuutta 1950-luvun ydinkokeiden runtelemilla ja ilmastonmuutoksen aikaansaaman merenpinnan nousun myötä hukkuvilla Marshallinsaarilla kuin pohjoisessa hyvinvointivaltiossa? Kun me akateemiset etuoikeutetut puhumme antroposeenin "meistä", joiden on toimittava, tulemmeko jälleen kerran asetelleeksi harteillemme sankaripioneerin ja kehityksen edelläkävijän viittaa (Yusoff, 2018)?

Mutta totta on, että jotain on tehtävä. Ja paljon tehdäänkin. Tätä kirjoittaessa kysymykset rakenteellisesta rasismista - joka kumpuaa orjuuttamisen oikeuttavista hyvin tahmeista rakennelmista - on tehty jälleen väistämättömiksi muun muassa mustien syrjintää vastustavan Black Lives Matter -liikkeen myötä. Globaali covid-19-pandemia on pakottanut tarkastelemaan ihmisten ja muiden eläinten suhteita ja niissä materialisoituvien epäoikeudenmukaisuuksien ja kaltoinkohteluitten viraaleja seurauksia - ja myös uusien lajien syntyä ja leviämistä osana antroposeenia.

Lukuisat zoonoosien tutkijat ovat argumentoineet, että nyt jos koskaan olisi teollistuneiden maiden syytä muuttaa pahasti vinksallaan olevaa suhdettaan muihin eläimiin ja ympäristöihin (esim. van Dooren, 2020; UN 2020). Edelleen, lapsuutta ja nuoruutta lukuisissa maissa on alkanut siivittää tuska maapallon tilasta, erityisesti ilmastonmuutoksesta. Huoli materialisoituu kollektiivisena liikehdintänä kestävän kehityksen puolesta, esimerkiksi Fridays For Future -liikkeenä, ja ilmastotekoina, kuten kierrätyksestä huolehtimisena ja kasvissyöjäksi ryhtymisenä.

Vaikka syöminen on välttämätöntä, ei ole yhdentekevää, mitä syömme. Tämän kertoo jo pitkällinen kädenvääntö ruokaympyrän sisällöstä. Syöminen on pakko, jota voidaan tarkastella vain sitä koskevien käytänteiden ja niihin sisältyvien halujen yhteydessä. Kiitänkin Mikko Rosenbergia syömisen nostamises- 
ta tarkastelunsa lähtökohdaksi ja pyrkimyksestä synnyttää itsekritiikkiä, samalla usuttaen kasvatustiedettä tarkastelemaan kestävämmän maailman kynnyskysymyksiä. Jos kasvatustiede tarkastelee niitä keinoja, joilla ihmisten ajatteluun, kokemukseen, tunteisiin ja toimintaan vaikutetaan ja pyritään vaikuttamaan, välttämättömyydet ovat oivallisia tarttumapintoja. Erityisen tärkeää tämä on kriittiselle monilajiselle kasvatustieteelle ja pedagogiikalle. Syöminen tuo monilajisuutemme väistämättömäksi tosiseikaksi. Ihmisyys on monilajinen suhde, kuten antropologi Anna Tsing (2012) kiteyttää.

Mutta vieraantuminen monilajisuudestamme on ollut niin tehokasta, että monilajisuuden ajatuksesta on tullut kumma. Yhteiskuntatieteiden eläinkäänne - sen tarkastelu, miten muut eläimet osallistuvat ja ovat olleet osallisina yhteiskuntien rakentumiseen on tärkeä liike, mutta ei synonyymi monilajisuudelle. Monilajinen tutkimus ja alkuperäiskansojen metafysiikoihin palaava tutkimus on huomannut tämän pyrkiessään tarkastelemaan "muotoja ja niiden moneuksia" (kinds and their multiplicities; van Dooren, Kirksey \& Münster 2016) usein etnografian keinoin.

Monilajinen empatia vaikuttaisi kuitenkin jossain määrin operoivan jakamalla tuntevat, ruuaksi määritellyt eläimet ja muut lajit vastakkaisiin kategorioihin, sillä ekologisemman tulevaisuuden kynnyskysymykseksi Rosenberg esittää laajamittaista siirtymistä lihansyönnistä kasvissyöntiin. Mutta liha ei liene yhtenäinen kategoria, kuten ei kasviskaan. On kait jonkinlainen ero sillä, onko kyseessä teollisesti tuotettu liha, jota on ruokittu brasilialaisella sademetsien tilalla kasvatetulla soijalla vai paikallinen peuranliha, tai onko kyseessä kiinalainen riisi, pohjoismainen kauravalmiste, kaupunkipuutarhan kesäkurpitsa vai pihalta kerätty maitohorsma.

Jos otamme todesta kirjoittajaakin innoittaneen alkuperäiskansojen kosmologian, jossa kaikki on tuntevaa ja tietoista, emme voi vetää lopullista rajaa lihan ja kasviksen välillä. On pikemminkin tarkasteltava yhdistelmiä ja niiden tuotoksia. Vaikka kirjoittajan, minun ja monen muun, toivoma siirtyminen lihansyönnistä kasvissyöntiin vaikuttaisi merkittävästi siihen, miten peltopinta-alaa käytetään, kun rehuntarve vähenee, se ei välttämättä muuta markkinatalouden logiikkaa aiempaa kohtuullisemmaksi ja kestävämmäksi.

\section{KOHTI KRIITTISTÄ MONILAJISTA KASVATUSTIEDETTÄ JA PEDAGOGIIKKAA}

Globaalin kasviksen polut voivat olla hyvinkin kiemuraisia ja perustua niin ihmisryhmien kuin maan orjuuttamiseen. Esimerkiksi suuria vesimääriä tarvitseva ja maaperää köyhdyttävä riisin tuotanto muodostaa lähes kymmeneksen ihmisten aiheuttamista metaanipäästöistä. Viljelijöiden keskuudessa velkavankeus ja sadon alihintainen myynti on tavanomaista, koska toisissa maissa riisiä viljellään tukien avulla, jotka mahdollistavat myynnin alle tuotantokustannusten (Hautamäki, 2015).

Osa nykypäivän orjuudesta ei ole enää suoranaista vangitsemista ja pakottamista vaan piiloutuu valinnan ja vapaaehtoisuuden verhon taakse. Aasiasta lentää vuosittain marjanpoimijoita keräämään suomalaisyrityksille marjoja niin vientiin kuin kotimaan markkinoille. Määrien on oltava niin suuria, että marjanpoimijan rahat riittävät korvaamaan lento- ja majoituskustannukset ja jotain jää vielä kotiinviemiseksikin. Tämä mahdollistuu ennen kaikkea sillä, että taloudellinen epätasa-arvo on niin suurta, että köyhien maiden ihmiset ovat valmiita lähtemään kauas kodistaan paremman toimeentulon toivossa. Tällainen orjuus jatkaa kolonialismin historiaa piiloutuen rehdiksi ja vapaaehtoiseksi vaihdoksi.

"Liha vai kasvis" on kysymys, josta on hyvä lähteä liikkeelle, mutta kriittisen pedagogiikan tulokulmasta sen tulisi myös herättää lisäkymyksiä: mikä liha, mikä kasvis, keiden kustannuksella, keiden hyödyksi? Näin kriittinen pedagogiikka ja kasvatustiede ei unohtaisi kiinnekohtaansa ihmisten välisissä epäoikeudenmukaisuuksissa, vaikka samalla laajentaisi tarkasteluaan ihmisten ja muiden eläinten, kasvien ja maan suhteisiin.

Valinta liha- ja kasvisruuan välillä pakottaa yksittäisiä ihmisiä miettimään suhdettaan muihin lajeihin, mutta ei välttämättä johda tarkastelemaan, missä määrin ihmisten, muiden eläinten ja maan alistaminen voivat lopulta olla saman dynamiikan eri ilmenemismuotoja. Kun kuluttajina kävelemme ruokakaupassa ja ladomme ostoskärrymme täyteen mitä erilaisimpia ruokia, joudumme monilajisessa empatiassamme luottamaan markkinatalouden kykyyn tuottaa eettisiä tuotteita. 


\section{OSA NYKYPÄIV̈̈N ORJUUDESTA \\ PIILOUTUU VALINNAN JA}

\section{VAPAAEHTOISUUDEN VERHON}

TAAKSE.

Joskus otamme käyttöön yksinkertaisen jaon lihaan ja kasvikseen, joskus jakolinja kulkee häkkieläinten, ”vapaiden” eläinten ja "luomueläinten” välillä. Välillä taas ajattelemme lihaksillamme ja tihrustamme proteiinipitoisuuksia ruokapakkauksista. Ja pitähän sitä toisinaan herkutellakin. Toisena hetkenä huomaamme sertifikaattien rivistön ja saatamme ajatella, että tästä tuotteesta varmaan jaetaan reilusti viljelijöille ja tuotantolinjojen työläisillekin. Mutta kaikki tämä tapahtuu ruokamarkkinoiden runsauden kontekstissa, jossa materian muuttuminen ruuaksi tarkoittaa sitä, että sen on voitava tuottaa lisäarvoa, olivat sertifikaatit mitä tahansa. Liha vai kasvis -keskustelu operoikin usein dominoivien valtamekanismien sisällä, kauppojen hyllyväleissä, valinnanvapauden nimissä.

Kathryn Yusoff (2018) muistuttaa, että juuri jano lisäarvon uuttamiseen niin ihmisistä ja muista eläimistä kuin maasta on perusta ei niinkään antroposeenille vaan miljardille mustalle antroposeenille. Miljardille orjuudelle. Ne meistä, joilla on varaa, voivat tyydyttäytyä päihdyttävän globaalin ruokabisneksen tarjoamaan määritelmään eettisyydestä. Kriittisen monilajisen pedagogiikan ja kasvatustieteen voisi olettaa kurkottavan tästä pidemmälle. Se on vaikeaa. Meillä on esimerkiksi hyvin vähän tietoa siitä, minkälaisia keskusteluja syömisen etiikasta kotien ja oppilaitosten ruokapöydissä käydään ja miten monilajisuutta käsitellään.

Teimme lapsuudentutkija Riikka Hohdin kanssa etnografiaa eräässä alakoulussa, jonka toisella luokka-asteella tarkasteltiin eläintä ilmiöperustaisen pedagogiikan avulla. Luokka perehtyi suomalaisiin eläimiin muun muassa vierailemalla säännöllisesti lähimetsässä, muovailemalla eläimiä savesta sekä tutustumalla lajikuvauksiin ja eläimistä kerrottuhin tarinoihin ja lauluihin. Meistä tutkijoista oli kiinnostavaa, että eläinprojektin lomassa oppilaat kä- vivät koulun ruokalassa syömässä lihatuotteita ja juomassa maitoa. Suomalaiset eläimet, joista lapset tekivät esitelmiään eivät sisältäneet yhtään tuotantoeläimiä tai koe-eläimiä vaan ainoastaan niitä "joita elää Suomen luonnossa”, mikä oli opettajan tuottama rajaus. Kun lapset kysyivät mahdollisuutta tehdä tutkimusta omasta kotieläimestään, syntyi keskustelua siitä, miten suomalaisuus määritellään. Me tutkijat mietimme erontekoja, joita eläinprojekti tuotti ja miten sen myötä tultiin ehkä vahvistaneeksi ajatusta eläimestä, joka elää ihmisestä etäällä ja ihmisen vaikutuksista vapaana. Mitä ovat nämä eläimet, jotka elävät Suomessa, mutta eivät lukeudu suomalaisiin eläimiin? Ikään kuin ihmisen ja eläimen välillä olisi vielä yksi sumea luokka, johon paradoksaalisesti kuuluvat ne eläimet, jotka tiiviimmin elävät ihmisten kanssa. Luonto siellä, kulttuuri täällä ja niiden välissä ne, jotka eivät oikein mahdu kumpaankaan.

Opettajan perusteltu näkemys oli, että ihmisten ja eläinten suhteisiin sisältyvät hankaukset, kuten oikeuskysymykset, tulee ottaa käsittelyyn sitten, kun lapset niitä esiin nostavat. Tätä tavoitetta kohti hän rakensikin luottamuksellista ja turvallista ilmapiiriä luokassa, mikä näkyi muun muassa siten, että oppilailla oli mahdollisuuksia raottaa tuntikehystä ja tuoda ilmoille tarinoita omista spesifeistä, vinkeistä ja haastavistakin eläinkohtaamisistaan. Laajemman tutkimushankkeemme etenemisen myötä huomasimme, että monet ja monen ikäiset lapset ovat kiinnostuneita yhdessäolon ja leikkimisen lisäksi eläinsuhteisiinsa liittyvistä hankauksista ja vaikeuksista. Se, ettei varmaksi tiedä miten toimia, on myös näitä suhteita ylläpitävä, syventävä ja kasvattava voima (ks. Tammi, Hohti, Rautio, Leinonen \& Saari 2020).

\section{EPÄPUHDASTA OSALLISTUMISTA MAAILMOJEN TEKOON?}

Olemme tutkimusryhmässämme tarkastelleet erinäisiä monilajisia ilmiöitä hoitamisena tai hoivana (care), pohjaten erityisesti feministitutkija Maria Puig de la Bellacasan (2017) teoriaan. Hoitaminen on epäpuhdasta osallistumista maailmojen tekoon. Hoitamiseen kuuluu kolme usein jännitteistä ulot- 
IHMISTEN TAVAT TIET $\dddot{A} \ddot{\text { JA }}$

OLLA MAAILMASSA KATTAVAT

VAIN OSAN NIIST $\ddot{A}$ TAVOISTA,

JOILLA MAAILMA TEKEE

ITSE $\ddot{A} \ddot{A N}$ HAVAITTAVAKSI JA

YMM ̈̈RRETT ̈̈V ̈̈KSI.

tuvuutta: materiaalinen työnteon ulottuvuus, tunteiden ulottuvuus ja eettis-poliittinen ulottuvuus (ks. Hohti \& Tammi 2019; Tammi, Hohti \& Rautio 2020; Tammi, Hohti, Rautio, Leinonen \& Saari 2020). Kuten syöminen, hoiva on sekä välttämätöntä että yhteiskunnallisiin käytänteisiin kietoutunutta, ei-viatonta ja ei-ongelmatonta.

Varhaiskasvatuksen tutkija Angela Molloy Murphyn (2020) käytännönläheinen artikkeli osoittaa, että hoitaminen ei takaa "onnellista loppua". Juuri siksi hoiva on tapa tehdä kritiikkiä, joka laajentaa ajatusta perustavasta mutta hämärästä suhteisuudesta, jossa kaikki liittyy kaikkeen, kohti tilanteista ja paikantunutta monisyisyyttä (Tammi, Hohti \& Rautio 2020). Ilman hoivaa mikään ei voi kasvaa, ei edes broileri, mutta yksioikoisesti ja lopullisesti reilumpaa maailmaa hoitaminen ei takaa. Sen sijaan se voi auttaa kysymään, miten hoitaa niin hyvin kuin mahdollista. Kerta toisensa jälkeen.

Kriittisen monilajisen kasvatustieteen tulokulmasta 'monilajinen empatia' on onnistunut käsite siinä, että se voi auttaa kutsumaan esiin kriittisiä jatkokysymyksiä eri kontaktialueilla. Keitä kohtaan empatiaa tuotetaan? Miten empatia on mukana, kun syömisen yhteydessä puhutaan terveydestä, taloudellisuudesta, ekologisuudesta, valinnanvapaudesta, traditiosta, lihaksista, kotimaisuudesta, likaisuudesta ja puhtaudesta, ja niin edelleen? Keitä kohtaan empatia on odotettua ja keitä kohtaan koettua empatiaa pidetään outona? Kun koulussa riehuu täiepidemia, miten monilajinen empatia sopii yhteen täishampoon myrkkyjen kanssa? Paljon puhutaan eläimistä, mutta entä kasvit? Mitä on vaatinut se, että tuossa on nyt kaurapelto? Entä miten empatia ja valta toimivat yhdessä: Milloin maailman köyhien ja alistettujen tulisi tuntea empatiaa rikkaiden ja etuoikeutettujen ihmisten kauppojen hyllyväleissä kokemaa valinnanvaikeutta, ilmastoahdistusta tai onnea kohtaan? Ja tämän sanottuani, miten yhdistää yleistetty ajatus yhtenäisestä 'lajista' ja tilanteisuus - lukemattomat "muodot ja niiden moneudet"?

Vaikka "monilajinen empatia kannustaa näkemään, kuuntelemaan ja kokemaan maailman sellaisena, jossa kaikki elämä on merkityksellistä ja tärkeää”, nälkä pakottaa tekemään valintoja ja syömään. Tieteen ja teknologian tutkija ja feministiteoreetikko Donna Haraway (2016) kehottaakin pysyttelemään ongelmallisuudessa tai vaikeudessa (staying with the trouble), sillä näin joudumme kerta kerran jälkeen tunnustamaan, ettemme tiedä ja silti toimimaan päästämättä itseämme suhteisuuden monimutkaisuuden yläpuolelle, jumalasemaan, ulkoavaruuden irralliseksi tarkkailijaksi. Avulias voi olla myös tieteenfilosofi ja eläintutkija Vinciane Despretin (2016) tapa kysyä, mitä tämä vierailu, kohtaaminen, tilanne, ilmiö tai suhde kysyy minulta tai tekee mahdolliseksi kysyä. Mitä pihvi lautasellani kysyy minulta? Naurukin voi olla hyvä opettaja.

Määrittelen 'empatian' tarkoittamaan affektiivista muutosvoimaa, jossa jokin toiseudesta asettuu osaksi itseä, avaten reittejä spekulaatiolle silti varmuutta tarjoamatta. Kun laajennetaan ihmisten välisistä suhteista ihmisen ja hänen ympäristönsä tekijöiden suhteisiin, empatian on mahdollista herättää kysymään, mitä oikeastaan tarkoittaa elää tällaisessa suhteisuudessa. Mitä mahtaa tarkoittaa ja miltä mahtaa tuntua elää näin? Seuraavan kysymyksen tulisi olla toimintaan suuntaava: mitä tämä värähdys kysyy minulta, mihin kutsuu minua, mihin velvoittaa? Metsästäjäystäväni kertoi minulle peuran tappamisen velvoittavan häntä metsää kohtaan. Se, mitä tämä tarkoittaa, riippuu siitä, mitä metsä vaikuttaisi kulloinkin tarvitsevan voidakseen niin hyvin kuin mahdollista.

Empatia on tärkeä osa projektia, jossa tehdään havaittavaksi hyvin- ja pahoinvoinnin kerrostumia niin ihmisten keskinäisissä suhteissa kuin ihmisten ja muiden olentojen välisissä suhteissa. Samalla empatia on epäpuhdasta, epävarmaa ja ei-viatonta. Se saattaa esimerkiksi tuottaa antropomorfisia oletuk- 
sia toisista eläimistä, vaikkapa sellaisia, että kaikki monilajisessa maailmassa kokevat maailmaa näkötai pääkeskeisesti. Tai että tärkeimpiä ovat ne, joilla on samat perustunteet kuin ihmisillä. Miten asettua sellaisen toisen asemaan, joka kokee maailman eri aistein kuin ihminen? Mitä empatia ihmisen ja koronaviruksen suhteessa voisi tarkoittaa? Ihmisten tavat tietää ja olla maailmassa kattavat vain osan niistä tavoista, joilla maailma tekee itseään havaittavaksi ja ymmärrettäväksi.

Antroposeenin ruokaympyrä ulottuu kotipöydästä kauppoihin ja tuotantolinjoille, navetoihin ja teurastamoihin, avohakkuille ja pelloille, lentokoneisiin ja rekkoihin, istuntoihin, raportteihin ja lupiin, troolareihin, voimaloihin ja tukiin, laboratorioihin, louhoksille ja öljykenttien poriin, pohjattomaan janoon ja lisääntyvään haluun, ja kaipuuseen, ja hoivaan. Kriittisen monilajisen tutkimuksen ja pedagogiikan tärkeä tehtävä voisi olla kulkea näitä tai muita reittejä ja paikantaa oikeudenmukaisuuden ja epäoikeudenmukaisuuden mekanismeja spesifeissä tilanteissa. Toisaalta. Ehkä meidän ei pitäisikään enää keskittyä tuntemamme myöhäisliberalistisen maailman parantamiseen ja muuttamiseen askel askeleelta sisällyttävämmäksi. Sen perusta on luotu alistamalla, tuhoamalla ja varastamalla. Pitäisikö sittenkin alkaa toimia tällaisen maailman päätökseen saattamiseksi, voidaksemme aloittaa toisenlaisista lähtökohdista (ks. esim. Yusoff, 2018)?

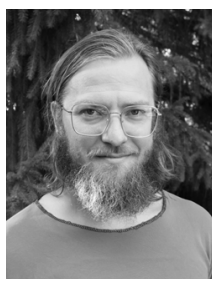

\section{TUURE TAMMI}

FT, tutkijatohtori

kasvatustieteiden tiedekunta

Oulun yliopisto

(D) http://orcid.org/0000-0002-

7582-8887

\section{LÄHTEET}

Despret, V. (2016). What Would Animals Say If We Asked the Right Questions? Minneapolis, MN: University of Minnesota Press.

Dooren, van, T. (2020). Pangolins and Pandemics: The Real Source of this Crisis is Human, not Animal. New Matilda 22.3.2020. https://newmatilda.com/2020/ 03/22/pangolins-and-pandemics-the-real-source-ofthis-crisis-is-human-not-animal/?utm_campaign= shareaholic\&utm_medium=facebook\&utm_source= socialnetwork\&fbclid=IwAR35ttch56VZkxkziPrzmsn」 ScOtwQQQDCnQqROKWEMnQTgHvFQ11xOL_F0 (10.8.2020).

Dooren, van, T., Kirksey, E., \& Münster, U. (2016) Multispecies Studies: Cultivating Arts of Attentiveness. Environmental Humanities 8(1), 1-23.

Haraway D. (2016). Staying with the Trouble: Making Kin in the Chthulucene. Durham, NC: Duke University Press.

Hautamäki, T. (2015). Velaksi viljelty basmatiriisi. Kuluttaja 15.4.2015. https://kuluttaja.fi/artikkelit/ velaksi-viljelty-basmatiriisi/ (10.8.2020).

Hohti, R., \& Tammi, T. (2019). The greenhouse effect: Multispecies childhood and non-innocent relations of care. Childhood 26(2), 169-185.

Mol, A. (2008). I eat an apple. On theorizing subjectivities. Subjectivity 22(1), 28-37.
Murphy, A. M. (2020). No Happy Endings: Practicing Care in Troubled Times. Journal of Childhood Studies 45(2), 7-13.

Puig de la Bellacasa, M. (2017). Matters of Care: Speculative Ethics in More Than Human Worlds. Minneapolis: University of Minnesota Press.

Tammi, T., Hohti, R., \& Rautio, P. (2020). Child-Animal Relations and Care as Critique. Journal of Childhood Studies 45(2), 1-6.

Tammi, T., Hohti, R., Rautio, P., Leinonen, R-M. \& Saari, M. (2020). Lasten ja eläinten suhteet. Monilajista yhteiseloa. Helsinki: Into Kustannus.

Tsing, A. (2012) Unruly Edges: Mushrooms as Companion Species. Environmental Humanities 1(1), 141-154.

Yusoff, K. (2018). A billion black Anthropocenes or none. University of Minnesota Press.

UN (2020). United Nations Environment Programme and International Livestock Research Institute. Preventing the Next Pandemic: Zoonotic diseases and how to break the chain of transmission. https:// www.ilri.org/publications/preventing-next-pandemiczoonotic-diseases-and-how-break-chain-transmission (10.8.2020) 